\title{
Predictive Value of Prognostic Nutritional index and Systemic Immune-Inflammation Index on Tumor Progression in Bladder Cancer Patients with After Radical Cystectomy
}

jiatong zhou

Tianjin Medical University Second Hospital

xitong $\mathrm{xu}$

Tianjin Medical University Second Hospital

ranlu liu (D 16622080858@163.com)

Tianjin Medical University Second Hospital

\section{Research}

Keywords: preoperative prognostic nutritional index, systemic immune-inflammation index, bladder cancer, radical cystectomy, inflammation

Posted Date: February 10th, 2021

DOl: https://doi.org/10.21203/rs.3.rs-201709/v1

License: (c) (1) This work is licensed under a Creative Commons Attribution 4.0 International License.

Read Full License 


\section{Abstract}

OBJECTIVES: The purpose of this study was to explore the predictive value of preoperative prognostic nutritional index(PNI) and systemic immune-inflammation index(SII) for local tumor stage in bladder cancer(BC) after radical cystectomy(RC).

METHODS: We researched our database between April 2011 and October 2019. There were 195 BC patients who underwent RC. The PNI and SIl were calculated using preoperative blood sample results. The predictive value of SII and PNI was analysed with univariate and multivariate Cox regression models. Significant $\mathrm{P}$ was $\mathrm{P}<0.05$.

RESULTS: Of patients, all patients were males with a mean age of $67.94 \pm 8.97 y$ years. Mean serum albumin was $42.13 \pm 4.28(\mathrm{~g} / \mathrm{L})$, mean PNI score was $51.29 \pm 6.09$ and mean SII was $661.67 \pm 506.22$. Multivariable Cox regression analysis demonstrated that $\mathrm{PNI}$ scores and SII could not play a significantly predictive factor between muscle invasive bladder cancer(MIBC) and non-muscle-invasive bladder cancer(NMIBC). While we also found PNI was an independent risk factors for predicting tumor stagep(pT囚3a and pT $\geq 3 a$ ).

CONCLUSIONS: Our research revealed that preoperative low PNI but not SIl could be used as an independent factor to predict worse pathologically stage(pT $\geq 3 a)$. We still need future studies with large cohorts to identify our results.

\section{Introduction}

Bladder cancer(BC) is currently one of the most common urinary system tumors affecting human health. $\mathrm{BC}$ is also the eighth leading cause of cancer death in men[1]. About $75 \%$ of patients with newly diagnosed bladder cancer are confined to the mucosa or urothelial tissue[2]. Radical cystectomy(RC) is the clinically accepted gold standard for the treatment of muscular invasive bladder cancer(MIBC) and non-muscle invasive bladder cancer(NMIBC) that is not effective by intravesical therapy $[3,4]$. Tumorrelated inflammation may affect the tumor cell gene expression to promote local tumor progression, metastasis, and reduce the effectiveness of tumor therapy[5]. Recently, many studies have found that some immune cells in the blood, including neutrophils, lymphocytes and monocytes, affect the tumor microenvironment through some signaling pathways, which may affect the local progression and metastasis[6]. The inflammatory cell markers neutrophil-lymphocyte ratio (NLR), platelet-lymphocyte ratio (PLR) have been used to assess tumor recurrence and survival rates[7, 8].The systemic immuneinflammation index(SII) has also recently been considered to represent systemic inflammation levels to better predict the prognosis of tumors including gastric cancer, colorectal cancer, esophageal cancer, and other tumors[9-11]. The Prognostic Nutritional Index (PNI)indicator was calculated from serum albumin and the total number of lymphocytes, and was first proposed in 1980[12]. So far, PNI has played an important role in predicting the prognosis of some urinary tumors[13, 14].

Currently, few studies have shown the relationship between PNI, SIl and the pathological stage of BC. Therefore, in order to study the predictive value of preoperative PNI and SII for pathological staging of BC 


\section{Patients And Methods}

The institutional review board and medical ethics committee of XXXX approved the research protocol of this study. We collected the medical data of 195 BC patients with RB in XXXX from April 2011 and October 2019. Participants were in this study if they (a) were pathologically diagnosed BC; (b) with complete data and laboratory results; The participants were excluded (a) who already had clinical evidence of inflammatory diseases such as infection; (b) using nonsteroidal anti-inflammatory drugs (c) without complete medical records and laboratory results. Each participant signed the informed consent for the data to be utilized in our study.The following demographic, clinical, and pathology data were collected from patient medical records. Pathologists assessed the tumor grade and stage according to the 2004 WHO classification system and tumor, lymph node, metastasis (TNM) rubric. The counts of neutrophil, lymphocyte, platelet and the albumin level was obtained with the hepatic function data before operation. The definitions of PNI, SII, NLR, and PLR were shown as follows: PNI = albumin $(\mathrm{g} / \mathrm{L})+5 \times$ total lymphocyte counts $\left(10^{9} / \mathrm{L}\right)$; SII = platelet $\times$ neutrophil/lymphocyte counts; NLR = neutrophil/lymphocyte counts; and PLR = platelet/lymphocyte counts. The study protocol was approved by the institutional Ethics Committee.

\section{Statistical analysis}

SPSS 22.0 was used for all statistical analyses. $x \pm s$ was used to evaluate continuous variables; frequency and scale were used to evaluate categorical variables. Chi-square test is used to analyze categorical variables. Receiver operating characteristic (ROC) curves were generated and areas under the curves (AUCs) were determined. Univariate and multivariate Cox regression analyses were performed to calculate corresponding odds ratios (ORs) and $95 \%$ confidence interval $(\mathrm{Cl})$. P values $<0.05$ were considered statistically significant.

\section{Results}

Our study included 195 participants totally according to the inclusion criteria. And all patients were male in this study, with the $67.94 \pm 8.97 y$ years. Among these patients, $38(19.5 \%)$ patients had diabetes, 67(34.4\%) patients had hypertension, $40(20.5 \%)$ patients had coronary heart disease. 69(35.4\%) patients were diagnosed the NMIBC, 126(64.6\%) patients had MIBC. 90(46.1\%) patients had pT $\geq 3 a, 105(53.9 \%)$ patients had $\mathrm{pT} \geq 3$ a. $37(18.9 \%)$ patients had incident prostate cancer after RC. the mean PNI was 51.29 \pm 6.09 , the mean serum albumin was $42.13 \pm 4.28(\mathrm{~g} / \mathrm{L})$, and the mean Sll score was $661.67 \pm 506.22$. Demographic and clinicopathological characteristics of the patients are summarized in Table 1. According to whether muscle-invasive or not, we divided the patients into NMIBC group and MIBC group. Clinicopathological characteristics of the patients are summarized in Table 2. In univariate analysis, we found that PNI, SII, NLR and PLR were all statistically significant for the incidence of MIBC. However, multivariate analysis showed that PNI, SII, NLR and PLR could not be used as independent factors to 
predict the risk of MIBC in Table 3. According to tumor stage, we divided the patients into $\mathrm{pT}<3$ a group and $\mathrm{pT} \geq 3$ 3a group in Table 4. In univariate analysis, we found that PNI, SII, NLR and PLR were all statistically significant for the incidence of worse stage. In multivariate analysis, we only found that preoperative PNI could be used as an independent predictor of tumor stage in Table 5( $p=0.014)$. ROC curve indicated that a PNI of 52.225 had 
Table 1

Characteristics of the study cohort

Mean \pm SD and $n(\%)$

Age(years) mean \pm SD

$67.94 \pm 8.97$

Gender, no. (\%)

Male

195(100)

Female

$\mathrm{BMI}$, mean $\pm \mathrm{SD}$

$24.11 \pm 3.41$

Diabetes, no. (\%)

Asent

$56(80.5)$

Present

38(19.5)

Hypertension, no. (\%)

Asent

128(65.6)

Present

67(34.4)

Coronary heart disease, no. (\%)

Asent

155(79.5)

Present

40(20.5)

$\mathrm{PNI}$, mean $\pm \mathrm{SD}$

$51.29 \pm 6.09$

SIl, mean \pm SD

$661.67 \pm 506.22$

$\mathrm{NLR}$, mean $\pm \mathrm{SD}$

$2.95 \pm 2.00$

$\mathrm{PLR}$, mean $\pm \mathrm{SD}$

$138.8 \pm 69.85$

Albumin, mean \pm SD

$42.13 \pm 4.28$

Bladder cancer(NMIBC or MIBC), no. (\%)

NMIBC

69(35.4)

MIBC

126(64.6)

pT,no.(\%)

$\mathrm{T}<3 \mathrm{a}$

105(46.1)

BMI body mass index, NLR neutrophil to lymphocyte ratio, PLR platelets to lymphocyte ratio, PNI prognostic nutritional index, SII systemic immune inflammation index, NMIBC non-muscle-invasive bladder cancer, MIBC muscle-invasive bladder cancer 


\begin{tabular}{|ll|}
\hline \multicolumn{1}{|c|}{} & \multicolumn{1}{l|}{ Mean \pm SD and $\mathbf{n}$ (\%) } \\
\hline $\mathrm{T} \geq 3 \mathrm{a}$, no. (\%) & $90(53.9)$ \\
\hline $\mathrm{N}_{0}$ & $68(34.9)$ \\
\hline $\mathrm{N}_{+}$ & $22(11.3)$ \\
\hline $\mathrm{N}_{\mathrm{X}}$ & $105(53.8)$ \\
\hline Incidental PCa, no.(\%) & \\
\hline Asent & $158(81.1)$ \\
\hline $\begin{array}{l}\text { Present } \\
\text { BMI body mass index, NLR neutrophil to lymphocyte ratio, PLR platelets to lymphocyte ratio, PNI } \\
\text { prognostic nutritional index, Sll systemic immune inflammation index, NMIBC non-muscle-invasive } \\
\text { bladder cancer, MIBC muscle-invasive bladder cancer }\end{array}$ \\
\hline
\end{tabular}


Table 2

Characteristics of the study between NMIBC and MIBC
$\operatorname{NMIBC}(n=69)$
$\operatorname{MIBC}(n=126)$
$\mathrm{p}$ value

Age(years) mean $\quad 68.04 \pm 8.38$

$67.88 \pm 9.34$

0.904

\pm SD

Gender, no. (\%)

Male

69(100)

126(100)

Female

$\mathrm{BMI}$, mean $\pm \mathrm{SD}$

$23.74 \pm 3.00$

$24.33 \pm 3.61$

0.241

Diabetes, no. (\%)

0.866

Asent

56(81.2)

101(80.2)

Present

13(18.8)

25(19.8)

Hypertension, no.

(\%)

$\begin{array}{lll}\text { Asent } & 48(69.6) & 80(63.5) \\ \text { Present } & 21(30.4) & 46(36.5)\end{array}$

Coronary heart

disease, no. (\%)

0.06

Asent

60(87.0)

95(75.4)

Present

9(13.0)

31(24.6)

$\mathrm{PNI}$, mean $\pm \mathrm{SD}$

$52.74 \pm 6.5$

$50.49 \pm 5.75$

$0.014^{\star}$

SII, mean \pm SD

$497.41 \pm 277.94$

$751.62 \pm 578.62$

$0.001^{*}$

NLR, mean $\pm S D \quad 2.32 \pm 1.07$

$3.30 \pm 2.29$

$0.001^{*}$

$\mathrm{PLR}$, mean $\pm \mathrm{SD} \quad 118.45 \pm 46.59$

$149.95 \pm 77.95$

$0.003^{*}$

Albumin, mean $\pm \quad 42.61 \pm 4.25$

$41.87 \pm 2.31$

0.253

SD

pT,no.(\%)

Tis or $\mathrm{T} 1$

69(100)

BMI body mass index, NLR neutrophil to lymphocyte ratio, PLR platelets to lymphocyte ratio, PNI prognostic nutritional index, SII systemic immune inflammation index, NMIBC non-muscle-invasive bladder cancer, MIBC muscle-invasive bladder cancer

* Statistically significant 


\begin{tabular}{|c|c|c|c|}
\hline & NMIBC $(n=69)$ & $\operatorname{MIBC}(n=126)$ & $\mathrm{p}$ value \\
\hline T2 & - & $36(28.6)$ & \\
\hline T3 & - & $63(50)$ & \\
\hline T4 & - & $27(47.4)$ & \\
\hline \multicolumn{4}{|c|}{ pN,no. (\%) } \\
\hline $\mathrm{N}_{0}$ & 23(33.3) & $45(34.9)$ & \\
\hline $\mathrm{N}_{1}$ & - & $22(17.1)$ & \\
\hline$N_{X}$ & $46(66.7)$ & $59(48)$ & \\
\hline \multicolumn{4}{|c|}{$\begin{array}{l}\text { Incidental PCa, } \\
\text { no.(\%) }\end{array}$} \\
\hline Asent & $54(78.3)$ & 104(82.9) & 0.293 \\
\hline Present & $15(21.7)$ & $22(17.1)$ & \\
\hline \multicolumn{4}{|c|}{$\begin{array}{l}\text { BMI body mass index, NLR neutrophil to lymphocyte ratio, PLR platelets to lymphocyte ratio, PNI } \\
\text { prognostic nutritional index, SII systemic immune inflammation index, NMIBC non-muscle-invasive } \\
\text { bladder cancer, MIBC muscle-invasive bladder cancer }\end{array}$} \\
\hline \multicolumn{4}{|c|}{ * Statistically significant } \\
\hline
\end{tabular}


Table 3

Univariate and Multivariate analysis for the association between muscle-invasive and patients and tumor characteristics

\begin{tabular}{|c|c|c|c|c|c|c|c|}
\hline \multirow[b]{2}{*}{ Variables } & & \multicolumn{3}{|c|}{$\begin{array}{l}\text { Univariate } \\
\text { analysis }\end{array}$} & \multicolumn{3}{|c|}{$\begin{array}{l}\text { Multivariate } \\
\text { analysis }\end{array}$} \\
\hline & & OR & $95 \mathrm{Cl} \%$ & $\begin{array}{l}\mathrm{p} \\
\text { value }\end{array}$ & OR & $95 \mathrm{Cl} \%$ & $\begin{array}{l}\mathrm{p} \\
\text { value }\end{array}$ \\
\hline Age & (continuous) & 0.998 & $\begin{array}{l}0.966- \\
1.031\end{array}$ & 0.904 & & & \\
\hline BMI & (continuous) & 1.055 & $\begin{array}{l}0.966- \\
1.154\end{array}$ & 0.235 & & & \\
\hline Albumin & (continuous) & 0.96 & $\begin{array}{l}0.896- \\
1.029\end{array}$ & 0.252 & & & \\
\hline PNI & (continuous) & 1.054 & $\begin{array}{l}1.027- \\
1.082\end{array}$ & $0.016^{*}$ & 0.987 & $\begin{array}{l}0.972- \\
1.001\end{array}$ & 0.077 \\
\hline SII & (continuous) & 1.002 & $\begin{array}{l}1.001- \\
1.003\end{array}$ & $0.001^{*}$ & 1.001 & $\begin{array}{l}0.999- \\
1.003\end{array}$ & 0.382 \\
\hline PLR & (continuous) & 1.009 & $\begin{array}{l}1.003- \\
1.015\end{array}$ & $0.003^{*}$ & 1.001 & $\begin{array}{l}0.992- \\
1.01\end{array}$ & 0.877 \\
\hline NLR & (continuous) & 1.492 & $\begin{array}{l}1.167- \\
1.906\end{array}$ & $0.001^{*}$ & 1.204 & $\begin{array}{l}0.801- \\
1.81\end{array}$ & 0.372 \\
\hline Diabetes & $\begin{array}{l}\text { (presence vs } \\
\text { absence) }\end{array}$ & 1.066 & $\begin{array}{l}0.506- \\
2.247\end{array}$ & 0.866 & & & \\
\hline Hypertension & $\begin{array}{l}\text { (presence vs } \\
\text { absence) }\end{array}$ & 1.232 & $\begin{array}{l}0.655- \\
2.319\end{array}$ & 0.518 & & & \\
\hline $\begin{array}{l}\text { Coronary heart } \\
\text { disease }\end{array}$ & $\begin{array}{l}\text { (presence vs } \\
\text { absence) }\end{array}$ & 2.175 & $\begin{array}{l}0.968- \\
4.887\end{array}$ & 0.06 & & & \\
\hline \multicolumn{8}{|c|}{$\begin{array}{l}\text { BMI body mass index, NLR neutrophil to lymphocyte ratio, PLR platelets to lymphocyte ratio, PNI } \\
\text { prognostic nutritional index, SIl systemic immune inflammation index, }\end{array}$} \\
\hline
\end{tabular}


Table 4

Characteristics of the study between $\mathrm{p} T \geq 3 \mathrm{a}$ and $\mathrm{pT}<3 \mathrm{a}$

\begin{tabular}{|c|c|c|c|}
\hline & $\mathrm{pT}<3 \mathrm{a}(\mathrm{n}=105)$ & $\mathrm{pT} \geq 3 \mathrm{a}(\mathrm{n}=90)$ & $\mathrm{p}$ value \\
\hline Age(years) mean \pm SD & $67.87 \pm 8.51$ & $68.01 \pm 9.58$ & 0.914 \\
\hline $\mathrm{BMI}$, mean $\pm \mathrm{SD}$ & $23.83 \pm 3.22$ & $24.44 \pm 3.62$ & 0.209 \\
\hline Diabetes, no. (\%) & & & 0.354 \\
\hline Asent & 83(79.1) & 74(77.9) & \\
\hline Present & $22(20.9)$ & $16(22.4)$ & \\
\hline Hypertension, no. (\%) & & & 0.488 \\
\hline Asent & $70(66.7)$ & $58(61)$ & \\
\hline Present & 35(33.3) & $32(39)$ & \\
\hline Coronary heart disease, no. (\%) & & & 0.037 * \\
\hline Asent & $89(84.8)$ & $66(69.5)$ & \\
\hline Present & 16(13.2) & $24(30.5)$ & \\
\hline $\mathrm{PNI}$, mean $\pm \mathrm{SD}$ & $52.24 \pm 6.33$ & $50.19 \pm 5.66$ & $0.019 *$ \\
\hline SII, mean \pm SD & $548.54 \pm 354.76$ & $793.66 \pm 617.79$ & 0.001 * \\
\hline NLR, mean $\pm S D$ & $2.45 \pm 1.25$ & $3.54 \pm 2.51$ & $<0.001$ * \\
\hline $\mathrm{PLR}$, mean $\pm \mathrm{SD}$ & $127.14 \pm 56.3$ & $152.4 \pm 81.47$ & $0.012 *$ \\
\hline Albumin, mean $\pm S D$ & $42.48 \pm 4.31$ & $41.72 \pm 4.27$ & 0.223 \\
\hline \multicolumn{4}{|c|}{$\begin{array}{l}\text { BMI body mass index, NLR neutrophil to lymphocyte ratio, PLR platelets to lymphocyte ratio, PNI } \\
\text { prognostic nutritional index, Sll systemic immune inflammation index }\end{array}$} \\
\hline * Statistically significant & & & \\
\hline
\end{tabular}


Table 5

Univariate and Multivariate analysis for the association between pathologic stage $(\mathrm{p} T \geq 3 \mathrm{a})$ and patients and tumor characteristics

\begin{tabular}{|c|c|c|c|c|c|c|c|}
\hline \multirow[b]{2}{*}{ Variables } & & \multicolumn{3}{|c|}{$\begin{array}{l}\text { Univariate } \\
\text { analysis }\end{array}$} & \multicolumn{3}{|c|}{$\begin{array}{l}\text { Multivariate } \\
\text { analysis }\end{array}$} \\
\hline & & OR & $95 \mathrm{Cl} \%$ & $p$ value & OR & $95 \mathrm{Cl} \%$ & $\begin{array}{l}\mathrm{p} \\
\text { value }\end{array}$ \\
\hline Age & (continuous) & 1.002 & $\begin{array}{l}0.971- \\
1.034\end{array}$ & 0.917 & & & \\
\hline BMI & (continuous) & 1.055 & $\begin{array}{l}0.97- \\
1.147\end{array}$ & 0.209 & & & \\
\hline Albumin & (continuous) & 0.96 & $\begin{array}{l}0.898- \\
1.025\end{array}$ & 0.223 & & & \\
\hline PNI & (continuous) & 0.944 & $\begin{array}{l}0.9- \\
0.991\end{array}$ & 0.021 * & 0.983 & $\begin{array}{l}0.97- \\
0.997\end{array}$ & $0.014 *$ \\
\hline SII & (continuous) & 1.001 & $\begin{array}{l}1.000- \\
1.002\end{array}$ & 0.001 * & 1.001 & $\begin{array}{l}0.999- \\
1.002\end{array}$ & 0.421 \\
\hline PLR & (continuous) & 1.006 & $\begin{array}{l}1.001- \\
1.011\end{array}$ & $0.016 *$ & 0.996 & $\begin{array}{l}0.988- \\
1.004\end{array}$ & 0.317 \\
\hline NLR & (continuous) & 1.427 & $\begin{array}{l}1.171- \\
1.740\end{array}$ & $<0.001$ * & 1.332 & $\begin{array}{l}0.936- \\
1.896\end{array}$ & 0.111 \\
\hline Diabetes & $\begin{array}{l}\text { (presence vs } \\
\text { absence) }\end{array}$ & 0.816 & $\begin{array}{l}0.399- \\
1,669\end{array}$ & 0.577 & & & \\
\hline Hypertension & $\begin{array}{l}\text { (presence vs } \\
\text { absence) }\end{array}$ & 1.056 & $\begin{array}{l}0.583- \\
1.914\end{array}$ & 0.857 & & & \\
\hline $\begin{array}{l}\text { Coronary heart } \\
\text { disease }\end{array}$ & $\begin{array}{l}\text { (presence vs } \\
\text { absence) }\end{array}$ & 2.023 & $\begin{array}{l}0.996- \\
4.107\end{array}$ & 0.051 & & & \\
\hline \multicolumn{8}{|c|}{$\begin{array}{l}\text { BMI body mass index, NLR neutrophil to lymphocyte ratio, PLR platelets to lymphocyte ratio, PNI } \\
\text { prognostic nutritional index, SIl systemic immune inflammation index, }\end{array}$} \\
\hline * Statistically & cant & & & & & & \\
\hline
\end{tabular}

maximum Youden index value (Fig. 1) (sensitivity $=64.4 \%$, Specificity $=54.3 \%$ ).

\section{Discussion}

Inflammation plays an important role in tumor occurrence, tumor progression and distant metastasis, and can also predict the prognosis of tumor patients[15]. We included the PNI, SII, NLR, PLR into this study, and found that PNI, SII, PLR, NLR could not predict the occurrence of muscular invasive BC, but on the other hand, our results revealed that PNI could be used as an independent predictor to predict whether the 
tumor has invaded beyond the bladder(pT $\geq 3 a)$, the lower the PNI may indicate the worse the pathological results.

Many studies have found that using inflammatory cell counts to calculate relevant inflammation markers, including NLR, PLR, LMR, has a meaningful relationship with the prognosis of tumors $[7,8]$. NLR revealed the response level and defense ability of the human immune system, which can reflect the body's immune surveillance and immunosurveillance to tumors[16].Dalpiaz et al reported that preoperative high NLR had a worse cancer-specific- as well as overall mortality after radical surgery for upper tract urothelial carcinoma (UTUC)[17]. Gondo et al also suggested that NLR could be used as an independent predictor to predict disease-specifific survival(DSS) in BC patients with $\mathrm{RC}$ [18]. In addition to the prognosis of patients with BC, NLR was also related to the pathological stage of the BC. In Tazeh et al's study, they described the significant association between the high NLR before transurethral resection of bladder tumor(s) (TURBT)and postoperative advanced tumor stage[19]. However, our study found that there was no statistical significance between NLR and the pathological stage of the tumor, which may be caused by the different surgical methods and the inclusion criteria.

SIl based on lymphocyte, neutrophil, and platelet counts. Compared with NLR, the appearance of SII is more representative of the level of human inflammatory response. Increased levels of inflammation represented by SII may indicate increased tumor burden or tumor progression[20]. Zhang et al proposed their research in 2019 which demonstrated that SIl can play as an independent predictor of overall survival (OS) in patients who have undergone radical cystectomy for bladder cancer, their research considered SII might to be a better predictor of prognosis than NLR, PLR[21]. Since many studies have found that SII plays an important role in predicting the prognosis of different tumors, we also analyzed level of SII and the incidence of worse pathological stage in BC patients after RC for the first time, although univariate analysis found that SII may be statistically related to the pathological stage after RC, SIl could not be used as an independent influencing factor to predict pathological stage.

PNI based on serum albumin and lymphocyte count which has been used as a significant predictor for prognosis of several urological cancers[22-24]. PNI not only indicates the level of inflammation in the human body, but also represents the nutritional level of the human body. Many studies on malnutrition associated with malignant tumors may lead to a poor prognosis. The composition of the human immune mechanism is inseparable from the support of nutrition. cancer-related malnutrition will disrupt the immune mechanism and break the normal immune balance, thereby reducing the inhibitory effect on tumor cells and promoting the proliferation of tumor cells, and the proliferation of tumor cells would also increase the consumption of human nutrition, such a vicious cycle would eventually lead to a poor prognosis[25, 26]. Xue et al thought low preoperative PNI was associated with worse survival outcomes in patients with UTUC[24]. Recently, Karsiyakali ed al research 164 primary BC patients who underwent TURBT and found that PNI is a potential predictor of preoperative tumor staging and an independent risk factor for predicting tumor staging[27]. Their results also indicated that PNI could significantly predict poor tumor stage, which is similar to the conclusion obtained by our research, but we believed that PNI could mainly predict the incidence of $\mathrm{p} T \geq 3$, and could not predict whether the tumor invades the 
muscular layer. their study only found that PNI could predict the incidence of $\mathrm{pT} \otimes 1$ after TURBT. The reason for this difference might be due to the different clinical stages of the patients and the different surgical methods.

A few limitations of our study should be considered. First, This study is an independent, single-center retrospective study. The clinical data collected may be biased, affecting the results. Besides, due to the small number of samples included in this study, The research results need to be further confirmed.

\section{Conclusion}

In conclusion, patients with low PNI had worse tumor stage( $\mathrm{pT} \geq 3 \mathrm{a})$. PNI is an independent predictor of oncologic outcomes in patients with BC after RC. Therefore, we suggested that Preoperative PNI can be combined with clinical bladder MRI to further increase the accuracy of clinical staging of BC, especially in pT3a.

\section{Declarations}

Acknowledgments

We owe our thanks to Tongxi Xu and Jiatong Zhou for their work on revising and data extracting in this manuscript.

Declarations

Funding

Tianjin Science and technology committee(19ZXDBSY00050)

Availability of data and materials

All data generated or analyzed during this study are included in this published article.

Further information

Not applicable.

Authors' contributions

Conception and Design: JZ and RL; Extraction of Data: XX and JZ;

Drafting the Article: JZ and RL; Revising It for Intellectual Content: JZ, RL; Final Approval of the Completed Article: JZ, RL. All authors read and approved the final manuscript.

Consent for publication 
Not applicable.

Conflict of interest

The authors declare no conflict of interest.

Statement of Ethics

All procedures performed in studies involving human participants were following the ethical standards of the institution and/or national research committee. This article does not contain any studies with animals performed by any of the authors.

\section{References}

1. Siegel RL, Miller KD, Jemal A. Cancer statistics 2016 CA: A Cancer Journal for Clinicians. 2016;66(1):7-30.

2. Compérat $E$, et al. Clinicopathological characteristics of urothelial bladder cancer in patients less than 40 years old. Virchows Arch. 2015;466(5):589-94.

3. Babjuk M, et al. EAU Guidelines on Non-Muscle-invasive Urothelial Carcinoma of the Bladder: Update 2016. Eur Urol. 2017;71(3):447-61.

4. Alfred Witjes J, et al. Updated 2016 EAU Guidelines on Muscle-invasive and Metastatic Bladder Cancer. Eur Urol. 2017;71(3):462-75.

5. Mantovani A, et al. Cancer-related inflammation. Nature. 2008;454(7203):436-44.

6. Hanahan D, Weinberg RA. Hallmarks of Cancer: The Next Generation. Cell. 2011;144(5):646-74.

7. Kaynar M, et al. Bladder cancer invasion predictability based on preoperative neutrophil-lymphocyte ratio. Tumor Biology. 2014;35(7):6601-5.

8. Marchioni M, et al. The Clinical Use of the Neutrophil to Lymphocyte Ratio (NLR) in Urothelial Cancer: A Systematic Review. Clin Genitourin Cancer. 2016;14(6):473-84.

9. Shi $\mathrm{H}$, et al., Nomogram Based on Systemic Immune-Inflammation Index to Predict Overall Survival in Gastric Cancer Patients. Disease Markers, 2018. 2018: p. 1-11.

10. Geng Y, et al., Systemic Immune-Inflammation Index Predicts Prognosis of Patients with Esophageal Squamous Cell Carcinoma: A Propensity Score-matched Analysis. Scientific Reports, 2016. 6(1).

11. Xie Q, et al., The systemic immune-inflammation index is an independent predictor of survival for metastatic colorectal cancer and its association with the lymphocytic response to the tumor. Journal of Translational Medicine, 2018. 16(1).

12. Liumbruno GM, et al. Recommendations for the use of albumin and immunoglobulins. Blood transfusion $=$ Trasfusione del sangue. 2009;7(3):216-34.

13. Peng D, et al., Preoperative Prognostic Nutritional Index is a Significant Predictor of Survival with Bladder Cancer after Radical Cystectomy: a retrospective study. BMC Cancer, 2017. 17(1). 
14. Kang M, et al. Prognostic Significance of Pre- to Postoperative Dynamics of the Prognostic Nutritional Index for Patients with Renal Cell Carcinoma Who Underwent Radical Nephrectomy. Ann Surg Oncol. 2017;24(13):4067-75.

15. Dougan M, Dranoff G. Immune Therapy for Cancer[J]. Annu Rev Immunol. 2009;27(1):83-117.

16. Block MS, Markovic SN. The Tumor/Immune Interface: Clinical Evidence of Cancer Immunosurveillance, Immunoediting and Immunosubversion. American Journal of Immunology. 2009;5(1):29-49.

17. Dalpiaz 0 , et al. Validation of the pretreatment derived neutrophil-lymphocyte ratio as a prognostic factor in a European cohort of patients with upper tract urothelial carcinoma. $\mathrm{Br} \mathrm{J}$ Cancer. 2014;110(10):2531-6.

18. Gondo T, et al. Prognostic Value of Neutrophil-to-lymphocyte Ratio and Establishment of Novel Preoperative Risk Stratification Model in Bladder Cancer Patients Treated With Radical Cystectomy. Urology. 2012;79(5):1085-91.

19. Tazeh NN, et al. Neutrophil to Lymphocyte Ratio (NLR) at the Time of Transurethral Resection of Bladder Tumor: A Large Retrospective Study and Analysis of Racial Differences. Bladder Cancer. 2017;3(2):89-94.

20. Hu B, et al. Systemic Immune-Inflammation Index Predicts Prognosis of Patients after Curative Resection for Hepatocellular Carcinoma. Clin Cancer Res. 2014;20(23):6212-22.

21. Zhang $W$, et al. Systemic immune-inflammation index predicts prognosis of bladder cancer patients after radical cystectomy. Annals of Translational Medicine. 2019;7(18):431-1.

22. Xue W, et al., Impact of the preoperative prognostic nutritional index on survival outcomes in upper tract urothelial carcinomas. Cancer Medicine, 2019.

23. Jeon HG, et al. Preoperative Prognostic Nutritional Index is a Significant Predictor of Survival in Renal Cell Carcinoma Patients Undergoing Nephrectomy. Ann Surg Oncol. 2016;23(1):321-7.

24. Tokunaga R, et al. Prognostic Nutritional Index Predicts Severe Complications, Recurrence, and Poor Prognosis in Patients With Colorectal Cancer Undergoing Primary Tumor Resection. Diseases of the Colon Rectum. 2015;58(11):1048-57.

25. Esfahani A, et al. Nutritional assessment of patients with acute leukemia during induction chemotherapy: association with hospital outcomes. Leuk Lymphoma. 2014;55(8):1743-50.

26. Morgan TM, et al. Preoperative Nutritional Status Is an Important Predictor of Survival in Patients Undergoing Surgery for Renal Cell Carcinoma. Eur Urol. 2011;59(6):923-8.

27. Karsiyakali N, Karabay E, Yucetas U. Predictive value of prognostic nutritional index on tumor stage in patients with primary bladder cancer. Arch Esp Urol. 2020;73(2):132-9.

\section{Figures}




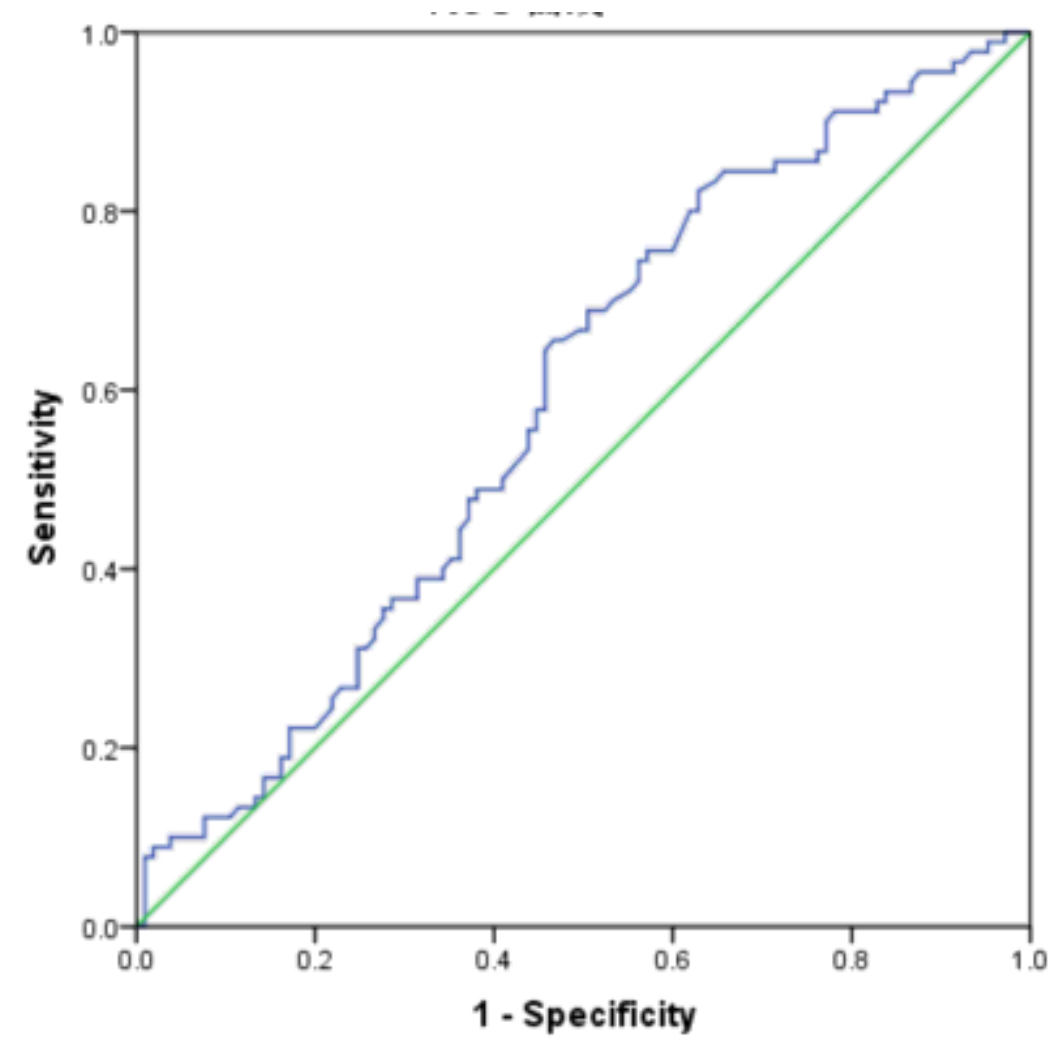

\section{Figure 1}

ROC curves in predicting $\mathrm{pT} \geq 3 \mathrm{a}$ by $\mathrm{PNI}$ (continuous, $\mathrm{AUC}=0.589$ ). $\mathrm{ROC}$ receiver operating characteristic, AUC area under curve 